\title{
A HERMENÊUTICA DE ALEXY E O CONFLITO ENTRE O DIREITO FUNDAMENTAL À MORADIA E AO AMBIENTE ECOLÓGICO EQUILIBRADO
}

\author{
Marina Maria Bandeira de Oliveira ${ }^{1}$ \\ Juliana Kryssia Lopes Maia ${ }^{2}$
}

RESUMO: Com crescimento populacional acelerado nos centros urbanos e dificuldade para prover moradia digna, cidadãos ocuparam áreas de preservação ambiental. São assegurados constitucionalmente o direito fundamental à moradia e o direito fundamental ao meio ambiente ecologicamente equilibrado, princípios que eventualmente colidem, pelo quê abordaremos o balanceamento e racionalidade proposto por Alexy, face à necessidade ponderação em favor de um deles para solução do caso concreto. Será utilizado o método dedutivo e as técnicas da pesquisa bibliográfica e jurisprudencial, especialmente do STF, destacando a possibilidade de regularização fundiária em casos específicos.

Palavras-chave: hermenêutica, colisão de direitos, moradia, meio ambiente

\section{THE HERMENEUTICAL OF ALEXY AND THE CONFLICT BETWEEN THE FUNDAMENTAL RIGHT TO DWELLING AND THE ECOLOGICALLY BALANCED ENVIRONMENT}

\begin{abstract}
With accelerated population growth in urban centers and difficulty in providing decent housing, citizens occupied areas of environmental preservation. The fundamental right to housing and the fundamental right to the ecologically balanced environment, principles that eventually collide, are constitutionally guaranteed, by which we will approach the balance and rationality proposed by Alexy, in view of the need to consider one of them in order to solve the concrete case. The deductive method and the techniques of bibliographical and jurisprudential research, especially the FTS, will be used, highlighting the possibility of land regularization in specific cases.
\end{abstract}

Key words: hermeneutics, collision of rights, housing, environment.

\section{INTRODUÇÃO}

1 Mestranda pelo UNISAL. Advogada. Professora. Especialista em Processo Civil, Direito Público, Direito Empresarial e Direito Imobiliário. Delegada Regional do CRECI/SP. marinabandeira@ hotmail.com

${ }^{2}$ Mestranda em direito pelo UNISAL. Advogada . Professora. Procuradora municipal. Especialista em direito civil e administrativo pela emerj. JULIANA julianamaia@hsmaia.com.br 
A sociedade brasileira deixou de ser rural e se tornou preponderantemente urbana, com crescimento e urbanização desordenados, irregularidades fundiárias, com dificuldade de acesso à moradia digna por significativa parcela da população, pelo quê face à relevância jurídica e social, para sua proteção, foi a moradia inserida em nossa Carta Maior como direito fundamental.

Encontra-se o meio ambiente equilibrado igualmente inserido no rol dos direitos fundamentais, pois a preservação dos recursos naturais é a única forma de se garantir o potencial evolutivo da humanidade, devendo ser preservado para os atuais e futuros habitantes do planeta.

Inobstante a relevância da preservação ambiental, não se pode considerá-lo de maneira isolada, sem considerar sua conciliação com o direito ao desenvolvimento e respeito das demais necessidades humanas, como a moradia.

Nexte contexto, necessário abordarmos a conceituração de princípios, direitos fundamentais, bem como a diferenciação entre regras e princípos, para então, enfrentarmos, utilizando-se de doutrinas especializadas, os direitos fundamentais à moradia e ao meio ambiente equilibrado; a teoria de Robert Alexy que defende a ponderação ou sopesamento para a escolha do princípio que será aplicado ao caso concreto; com análise de julgados do STF nos quais a temática foi enfrentada e o critério utilizado para relevância da moradia em inúmeros casos concretos, inclusive com possibilidade de regularização fundiária.

\section{PRINCÍPIOS GERAIS DE DIREITO E PRINCÍPIOS CONSTITUCIONAIS.}

Princípio relaciona-se à origem ou começo, pelo quê no Direito destacam-se os princípios gerais de Direito, os princípios constitucionais e os infraconstitucionais.

Os princípios gerais de direito orientam de forma ampla o pensamento jurídico, especialmente o processo de aplicação e interpretação, em patamar superior às relações jurídicas, tratando-se (STRECK, 2004, p. 108) de normas de Direito Natural, verdades jurídicas universais e imutáveis, que devem ser aplicadas ao caso concreto, na medida em que (BOBBIO, 2006, p.42)

o Estado é constituído com base no estado de natureza em razão do contrato social e na organização ghido Estado que conservam direitos naturais fundamentais, de maneira que 
(STRECK, 2004, p. 110) "adquirem um significado apenas quando considerados em conjunto com o restante do sistema jurídico; daí a necessidade de se pressupô-los como uma totalidade”.

Os princípios constitucionais são positivados nas constituições versando sobre direitos fundamentais, podendo ser explícitos (escritos) ou implícitos (deduzida sua existência em face do contexto e intenção), de maneira que é (BOBBIO, 2006, p. 21-22) posto pelo Estado e portanto conhecido em razão da vontade do legislador, destacando que (ALEXY, 2003) exercem efeito irradiante para todo os sistema jurídico e são onipresentes.

Por fim, os direitos humanos como conhecidos na atualidade, originaram do pensamento filosófico greco-romano, ideais do cristianismo e direito natural, sendo certo ainda que a ideia de direito fundamentais é precedente ao constitucionalismo, pois este apenas consagrou rol mínimo de direitos humanos documento escrito e derivado da vontade do povo.

\section{DIREITOS HUMANOS E DIREITOS FUNDAMENTAIS}

Direitos Humanos e portanto Fundamentais, são relacionados ao mínimo imprescindível para a subsistência do ser humano, de maneira que devem ser atendidos e assegurados à todos. Deve ser concebida (SERRANO, 2017, p. 180) da forma mais ampla possivel, sendo concebida como ideal orientador para o alcance da Vida, da Paz, da Justiça, da Dignidade e da Convivência Humana, sendo decorrentes da existência do ser humano, que é sua fonte e razão direta. Mostrando-se relevante sua positivação (BASTOS, 2002, p. 258-259):

\footnotetext{
Em nossa época é quase que obrigatório o fazer constar em todo Texto Constitucional uma declaração de direitos que dizem respeito ao próprio homem. Isso ocorre por força de uma longa evolução histórica, que parte da Idade Média e chega até os dias atuais (...) Eles apresentam sempre uma nota caracterizadora, qual seja, a de prescindirem de qualquer fato aquisitivo (...) a função básica do direito é constituir uma situação, um espaço jurídico dentro do qual a personalidade humana possa se desenvolver, sem estar sob restrições legais que violentem o livre desabrochar de sua personalidade.
}

Assim, a Constituição pode ser definida como um núcleo jurídico fundamental com capacidade de fixar os procedimentos para proteção dos direitos basilares do homem, resolução 
de conflitos emergentes, forma e a unidade política das tarefas estatais, cuja tarefa primordial é estruturar a sociedade, elencando as garantias e direitos fundamentais.

Direitos Humanos (SERRANO, 2017, p. 182) identificados com a plenitudo do direito à vida, sob o aspecto físico e moral, conferindo condições para desdenvolvimento humao, assim, consagram a dignidade da pessoa humana como seu fim, pelo quê deve ser comprendida de forma dinâmica, inobstante, valores como liberdade, igualdade, democracia, bem-estar e felicidade, sejam clausulas abertas e portanto inexauríveis.

Embora os direitos fundamentais (BOBBIO, 2004, p. 9) sejam direitos do homem e por si mesmos universais, temos por certo que são também constitucionais na medida em que inseridos na Carta Magna. Sua evolução acompanha a evolução da sociedade, de maneira que podem sofrer limitações ou ampliação com base nos anseios sociais. Assim, direitos absolutos como a propriedade (no século XVIII) sofreram consideravel limitação na sociedade atual e novos foram incluidos. Conclui-se portanto que o fundamental em um contexto social pode não ser em outro, influenciando principalmente no contexto prático de aplicação do direito.

Dessa forma, conclui-se que os direitos fundamentais não são absolutos pelo quê concluimos que seu exercício está sujeito a limites, e, por serem geralmente estruturados como princípios, os direitos fundamentais, em inúmeras situações, são aplicados mediante ponderação face à análise do caso concreto.

A colisão entre normas constitucionais tem potencializado inúmeros debates na sociedade contemporânea, na medida em que estas, originadas do processo constituinte originário, não guardam hierarquia entre si, ou preponderância de uma em face da outra.

\section{DO CONFLÍTO ENTRE PRINCÍPIOS PARA ALEXY}

As colisões de direitos fundamentais devem ser analisadas como uma colisão de princípios, sendo que o processo para a solução de ambas as colisões é a ponderação. Para Alexy (ALEXY, 2003) "Valores e princípios tendem a colidir. Uma colisão de princípios só pode ser resolvida pelo balanceamento". 
Assim, todos os princípios a priori têm o mesmo valor e peso, pelo quê em caso de colisão devem ser ponderados frente ao caso concreto verificando qual prefalecerá para concretização da justiça.

O conflito não pode ser eliminado por meio da exclusão de um dos princípios; não sendo também possivel o estabelecimento de regra pela qual um prepondera em face do outro. Assim, não haverá preferência absoluta mas condicionada, face à análise do caso concreto. Alexy (ALEXY, 2003) escreve:

[...] a otimizaçaõ relativa de princípios concorrentes consiste em nada mais do que no balanceamento desses princípios. A Lei do Balanceamento demonstra que o balanceamento pode ser dividido em três etapas ou estágios. O primeiro estágio é do do estabelecimento do grau de não-satisfação ou de detrimento do primeiro princípio. Segue-se um segundo estágio, no qual a importância de satisfazer o princípio concorrente é estabelecida. Finalmente, o terceiro estágio responde à questão de saber se a importância de se satisfazer ou não o princípio concorrente justifica o detrimento ou a não-satisfação do primeiro.

A solução da colisão de princípios deverá ser verificada no caso concreto mediante as etapas da ponderação, devendo os princípios ser aplicados para atendimento das necessidades da sociedade.

Assim, considerando os princípios como um mundo de dever ser ideal, não estabelecendo como as coisas são, mas meramente como devem ser ou como sobre elas pensar, evitando contradições. Princípios são válidos e hierarquicamente equivalentes, sendo a colisão ocorrida no caso concreto, de maneira que um princípio limita o efeito do outro.

As colisões de direitos fundamentais devem ser consideradas como uma colisão de princípios, podendo ser adotado critério hermenêutico de Alexy utilizando como processo de solução para a colisão, a ponderação.

Critica relevante à ponderação é o fato de que esta fica submetida ao arbítrio de quem a realiza, assim, é possivel a obtenção de resultados diferentes, assim, a ponderação não garante o ideal da única decisão jurídica correta, contudo, oportuniza um modelo de fundamentação racional. A determinação ou fundamentação da razão de um princípio preponderar sobre outro, possibilita controle crítico e lógico da decisão.

Revista de Direito Urbanístico, Cidade e Alteridade | e-ISSN: 2525-989X | Belém | v. 5 | n. 2 |

p. 63 - 80 | Jul/Dez. 2019. 
A justificação baseada na lei da ponderação não garante um procedimento definitivo de decisão, não significando que ela seja inviável. Ela não diz qual é a resposta jurídica correta, mas diz o que deve ser justificado para construir uma resposta correta. Alexy aborda a justificação indicando que a correta da decisão racional funda-se no plano da argumentação jurídica, que pode ocorrer pela argumentação jurídica ou argumentação prática, volta à utilização de princípios morais, valores éticos, ideais políticos e outros.

Feitas tais considerações, analisaremos a essencia do direito fundamental à moradia e do direito fundamental ao meio ambiente equilibrado, seus conflitos e ponderação ou balanceamento realizados pelos tribunais para solução do conflito e concretização da justiça no caso concreto.

\section{DIREITO FUNDAMENTAL À MORADIA}

O crescimento desordenado das cidades, atrelado ao aumento populacional em face do êxodo rural foi vetor da degradação na qualidade de vida, considerando que o baixo poder aquisitivo da população viabilizou a ocupação de loteamentos irregulares ou favelas, com condições de evidente ausência de dignidade.

Estimulado pelos debates internacionais sobre o tema ${ }^{3}$, o Brasil, reconhecendo a moradia como elemento essencial à dignidade da pessoa humana, positivou-o no artigo $6^{\circ}$ da Carta Magna, por meio da Emenda Constitucional n. 20 de 2000, reconhecendo como inerente à dignidade da pessoa humana, portanto, inadmissivel na sociedade contemporânea o expressivo número de pessoas sem condições mínimas de subsistência e sem acesso à necessidades primárias relacionadas à moradia.

Note-se que (SAULE JR, 2004, p. 152) “o direito à moradia como integrante dos direitos sociais, para ter eficácia jurídica e social, pressupõe a ação positiva do Estado por meio da

\footnotetext{
${ }^{3}$ Destacando-se a Conferência das Nações Unidas sobre Assentamentos Humanos - Habitat I, ocorreu em 1976, e realizou-se em Vancouver (Canadá), que resultou na "Declaração de Vancouver sobre Assentamentos Humanos", com 64 recomendações de ações nacionais para promover políticas adequadas nos âmbitos locais e regionais, urbanos e rurais. Todos os dados e informações foram retirados do sítio eletrônico da Oraganização das Nações Unidades (ONU), disponível em: https://nacoesunidas.org/agencia/onuhabitat/ e no sítio eletrônico dos objetivos da Agenda Habitat, disponível em: http://mirror.unhabitat.org/downloads/docs/1176_6455_The_Habitat_Agenda.pdf
} 
execução de políticas públicas, no caso, em especial, da promoção da política urbana e habitacional". É certo que a eficácia dos direitos sociais esta diretamente relacionada à obrigatoriedade do Poder Público na promoção de políticas públicas que viabilizem seu direito, sob pena de tornar o texto constitucional mera ficção jurídica.

$\mathrm{O}$ direito social à moradia não pode ser confundido com o direito individual à propriedade, por ter este natureza individual, sendo destinado ao titular do bem que poderá exercê-lo, contudo o direito à moradia é coletivo, amplo e inerente à condição humana, justificando sua preponderância e essencialidade. Tem-se portanto que a moradia é irrenunciável, indissociável de sua vontade e indisponível, configurando, portanto, um bem extrapatrimonial.

Tem-se, portanto, que é dever do Estado, nas suas três esferas, promover programas de construção de moradias e melhoria das condições habitacionais e de saneamento básico (artigo 23, inciso IX), sendo a normatização infraconstitucionais robusta quanto à proteção da moradia, com destaque para a positivação do direito à cidade (Lei n. 10.257/01), regularização fundiária (Lei n. 11.977/2009 e Lei n. 13.465/2017) e outras.

\section{DIREITO FUNDAMENTAL AO MEIO AMBIENTE EQUILIBRADO}

Combater a crise ambiental é grande desafio da sociedade atual, pois não se pode mais admitir que o meio ambiente seja negligenciado em benefício do desenvolvimento econômico, provocando degradação que coloca em risco a própria sobrevivência da humanidade e do nosso planeta. Assim, Norberto Bobbio (BOBBIO, 1992, p. 43) ao se referir ao problema dos direitos humanos de terceira geração, afirmou que o mais importante deles é o reivindicado pelos movimentos ecológicos: o direito de viver num ambiente não poluído.

O direito ao meio ambiente e o seu reconhecimento como um direito fundamental do ser humano surgiu com a Conferência das Nações Unidas sobre o Meio Ambiente Humano, realizada pela ONU em 1972, na cidade de Estocolmo, a qual deu origem ao Programa das Nações Unidas 
para o Meio Ambiente. Como resultado das discussões dessa conferência, foi elaborada a "Declaração de Estocolmo"4.

A Constituição Federal brasileira, visando proteger o direito fundamental ao meio ambiente equilibrado, positivou-o no artigo 225, e destacou tratar-se de bem de uso comum do povo e um direito de todos os cidadãos, das gerações presentes e futuras, estando o Poder Público e a coletividade obrigados a preservá-lo e a defendê-lo.

Assim, o conceito de meio ambiente supera a denominação de que é um bem público, tendo em vista que não é só do Estado, mas também da coletividade, o dever de defendê-lo e preservá-lo, na medida em que (SILVA, 2007, p. 28) sua degradação prejudica não só o bem estar, mas a qualidade de vida ou a existência da vida do ser humano.

O Direito ao meio ambiente equilibrado é social porque, como bem de uso comum do povo (portanto, difuso) integra o patrimônio coletivo, logo, não é possível, em nome deste direito, apropriar-se individualmente de parcelas do meio ambiente para consumo privado, pois a realização individual deste direito fundamental está intrinsecamente ligada à sua realização social. Ademais, é intergeracional porque a geração presente, deve defende-lo e preserva-lo para as futuras gerações.

Destacando no âmbito infraconstitucional a Lei n. 10.257/2001 (Estatuto da Cidade) que regulamentou os artigos 182 e 183 da Carta Magna, estabelecendo diretrizes gerais da polícia urbana e dentre outras disposições legitimando o Poder Público a intervir na propriedade particular que não esteja cumprindo sua função social, viabilizando o direito à moradia.

\subsection{Das áreas de preservação permanente}

As Áreas de Preservação Permanente são espaços territoriais especialmente protegidos, que podem ser cobertos ou não por vegetação nativa, com a função ambiental de preservar os recursos hídricos, a paisagem, a estabilidade geológica e a biodiversidade, facilitar o fluxo gênico

\footnotetext{
${ }^{4}$ A integra e pontos relevantes da Declaração de Estocolmo sobre o ambiente humano - 1972, poderá ser verificada em: $\quad$ http://www.direitoshumanos.usp.br/index.php/meio-ambiente/declaracao-de-estocolmo-sobre-o-ambientehumano.html.
} 
de fauna e flora, proteger o solo e assegurar o bem-estar das populações humanas, tuteladas pelo capítulo II, do código florestal 12.651/2012, e regulamentada de acordo com o inciso III, $\S 1^{\circ}$ do artigo 225 da Constituição Federal.

Com função variada, objetivam proteção dos recursos hídricos, proporcionando cobertura e filtros para preservação das águas; controlam a temperatura, filtram os agrotóxicos, pelo quê, é cediço que a ocupação destas áreas prejudica o curso dos rios, potencializa a poluição, prejudica o fornecimento de água, interferindo de forma direta na vida e saúde da população. Ademais, mantém a vegetação nativa, amenizando temperatura e mantendo a umidade do ar, sendo fundamental para desenvolvimento de cidades sustentáveis.

Destaca-se ainda o objetivo de proteção das encostas especialmente aquelas com declividade superior a $45^{\circ}$ e topos de morro, montes, montanhas e serras, áreas frágeis e sujeitas a desbarrancamentos e deslizamentos de solo ou rochas; previnir o assoreamento e a ocorrência de enxurradas e deslizamentos de terra, contribuindo para segurança da população localizada em sua proximidade. No mais, protege a biodiversidede da fauna e da flora.

\subsubsection{Da regularização fundiária em área de preservação permanente}

Para regularização, além da consolidação de moradia no local e impossibilidade/inviabilidade de locomoção para outro local, a área deverá conter um mínimo de infraestrutura e estar localizado em um local adequado que não ofereça riscos a moradores (desmoronamentos, enchentes) ou a coletividade pela possibilidade de poluir a rede de abastecimento de água.

Assim, a nova legislação (Lei n. 13.465/17), no tocante às áreas de preservação permanente, dispõe (LEITE, 2017):

\footnotetext{
A Medida Provisória $n^{\circ} 759$ remeteu à legislação ambiental a disciplina das áreas de preservação permanente ocupadas $\left(\operatorname{art.} 9^{\circ}, \S^{\circ}\right)$. Atualmente, os arts. 64 e 65 da Lei $n^{\circ}$ 12.651/12 tratam do assunto. 13 Por primeiro, é preciso entender o contexto em que a Lei $\mathrm{n}^{\circ} 12.651 / 12$ permite a intervenção em área de preservação permanente. Com efeito, esta é autorizada somente nos casos de utilidade pública, interesse social e baixo impacto ambiental $\left(\operatorname{art.} 8^{\circ}\right.$ ). As hipóteses de interesse social estão elencadas no art. $3^{\circ}$, IX, dispondo sua alínea "d": "a regularização fundiária de assentamentos humanos
} 
ocupados predominantemente por população de baixa renda em áreas urbanas consolidadas". Portanto, a consolidação da ocupação de área de preservação permanente na regularização fundiária referida pela Lei $n^{\circ}$ 12.651/12 somente é admitida quando se referir a assentamentos ocupados predominantemente por população de baixa renda. Assim, como normalmente nesses casos a regularização será de interesse social, praticamente será mínima a ocorrência de consolidação de área de preservação permanente na regularização por interesse específico - pode-se pensar no caso em que, a despeito da população ser de baixa renda, o Município não qualificou o núcleo como de interesse social por ausência de outros requisitos previstos em lei municipal ou na regulamentação da própria Medida Provisória. Além disso, tanto o art. 64 quanto o art. 65 da Lei $n^{\circ} 12.651 / 12$ estabelecem que a ocupação de área de preservação permanente somente é possível em se tratando de núcleos urbanos consolidados - conceito dado pela Medida Provisória $n^{\circ} 759$, em seu art. 21, $^{\circ}$ : tratase dos núcleos urbanos informais existentes na data de publicação da Medida Provisória e com características que indiquem sua irreversibilidade, como "o tempo da ocupação, a natureza das edificações, a localização das vias de circulação e a presença de equipamentos públicos, entre outras circunstâncias a serem avaliadas pelos Municípios ou pelo Distrito Federal". Caberá ao Município, em decisão motivada, qualificar como consolidado determinado assentamento.

$[\ldots]$

É necessário apresentar no bojo do projeto de regularização fundiária um estudo técnico minucioso, a ser elaborado por profissional competente, que analise as condições da ocupação da área de preservação permanente e que demonstre que sua consolidação implica em "melhorias ambientais em relação à situação anterior, inclusive por meio de compensações ambientais, quando for o caso" (art. $9^{\circ}, \S 3^{\circ}$, da Medida Provisória $n^{\circ}$ 759).

\section{CONFLITO ENTRE O DIREITO FUNDAMENTAL À MORADIA E DIREITO FUNDAMENTAL AO MEIO AMBIENTE EQUILIBRADO}

Cediço que o aumento demográfico provocado pelo êxodo rural e a impossibilidade de absorção do seu contingente pela cidade, potencializado pela omissão do Estado brasileiro, quanto a implantação de políticas públicas leva milhares de brasileiros a construir as suas casas de maneira irregular em áreas impróprias sem as condições mínimas de estrutura urbana. Não é raro que essas moradias acabem sendo construídas em áreas de proteção ambiental, ocasionando a colisão entre os direitos fundamentais à moradia e ao meio ambiente ecologicamente equilibrado.

Assim (MELO, 2010, p. 28-33),

O adensamento surgido com a migração impossibilitou a absorção do seu contingente pela cidade, o que, aliado ao aumento demográfico, provocou, ao mesmo tempo, a 
urbanização brasileira e a segregação espacial da população de baixa renda, sem prejuízo de considerar o papel do Estado como contributivo para a segregação e a informalidade urbana vivenciadas atualmente [...] a lógica da exclusão social faz parte do modelo de desenvolvimento urbano como parte e consequência "natural" do modelo econômico adotado, o que não difere da maioria dos países latino-americanos. As questões urbanas se agravam tanto quanto os direitos humanos são reivindicados e a cada dia aumenta o número de pessoas circulando, migrando para as cidades, sejam advindas do campo ou de outros centros urbanos, em busca de emprego, trabalho para assumir um novo emprego, e todos necessitam, basicamente, acessar uma das principais funções da cidade: a moradia

Conforme já abordado neste trabalho, face à escassez de espaço urbano adequado, referida população marginalizada e vulnerável não encontra alternativa senão os assentamentos informais, muitas vezes localizados em áreas de preservação ambiental, surgindo o conflito fático entre o direito à moradia e o direito de preservação ambiental, enfoque principal do presente estudo.

Observe-se que considerando que ponderação fica submetida ao arbítrio de quem a realiza, teremos a obtenção de resultados diferentes face o conflito dos mesmos principios (moradia e meio ambiente equilibrado).

Indicando a preponderância do direito fundamental à moradia, quando comprovadamente necessária para o exercício da cidadania para populações em situação de vulnerabilidades, destacamos:

“AÇÃO CIVIL PÚBLICA. DIRETO AMBIENTAL. DIREITO À MORADIA. DIREITO INTERNACIONAL DOS DIREITOS HUMANOS. DESOCUPAÇÃO FORÇADA E DEMOLIÇÃO DE MORADIA. ÁREA DE PRESERVAÇÃO PERMANENTE. POSSE ANTIGA E INDISPUTADA. AQUIESCÊNCIA DO PODER PÚBLICO. DISPONIBILIDADE DE ALTERNATIVA PARA MORADIA. TERRENO DE MARINHA. DESNECESSIDADE DE PERÍCIA JUDICIAL. PROTEÇÃO À DIGNIDADE HUMANA, DESPEJO E DEMOLIÇÃO FORÇADAS PARA PROTEÇÃO AMBIENTAL. PREVENÇÃO DE EFEITO DISCRIMINATÓRIO INDIRETO. (...) 2. A área de restinga, fixadora de dunas, em praia marítima, é bem público da União, sujeito a regime de preservação permanente. 3 . A concorrência do direito ao ambiente e do direito à moradia requer a compreensão dos respectivos conteúdos jurídicos segundo a qual a desocupação forçada e demolição da moradia depende da disponibilidade de alternativa à moradia. 4. Cuidando-se de família pobre, chefiada por mulher pescadora, habitando há largo tempo e com aquiescência do Poder Público a área de preservação ambiental em questão, ausente risco à segurança e de dano maior ou irreparável ao ambiente, fica patente o dever de compatibilização dos direitos fundamentais envolvidos. 5. O princípio de interpretação constitucional da força normativa da Constituição atenta para a influência do conteúdo jurídico de um ou mais direitos fundamentais para a compreensão do conteúdo e das exigências normativas de 
outro direito fundamental, no caso, o direito ao ambiente e direito à moradia. 6 . Incidência do direito internacional dos direitos humanos, cujo conteúdo, segundo o Alto Comissariado para Direitos Humanos da ONU (The Right to adequato housing (art. 11.1): forced evictions: 20/05/97. CESCR General comment 7), implica que "nos casos onde o despejo forçado é considerado justificável, ele deve ser empreendido em estrita conformidade com as previsões relevantes do direito internacional dos direitos humanos e de acordo com os princípios gerais de razoabilidade e proporcionalidade" (item 14, tradução livre), "não devendo ocasionar indivíduos"sem-teto"ou vulneráveis à violação de outros direitos humanos. Onde aqueles afetados são incapazes para prover, por si mesmos, o Estado deve tomar todas as medidas apropriadas, de acordo com o máximo dos recursos disponíveis, para garantir que uma adequada alternativa habitacional, reassentamento ou acesso a terra produtiva, conforme o caso, seja disponível."8. Proteção da dignidade da pessoa humana, na medida em que o sujeito diretamente afetado seria visto como meio cuja remoção resultaria na consecução da finalidade da conduta estatal, sendo desconsiderado como fim em si mesmo de tal atividade.9. Concretização que busca prevenir efeitos discriminatórios indiretos, ainda que desprovidos de intenção, em face de pretensão de despejo e demolição atinge mulher chefe de família, vivendo em sua residência com dois filhos, exercendo, de modo regular, a atividade pesqueira. A proibição da discriminação indireta atenta para as consequências da vulnerabilidade experimentada por mulheres pobres, sobre quem recaem de modo desproporcional os ônus da dinâmica gerados das diversas demandas e iniciativas estatais e sociais." grifei

(TRF-4 - AC: 3887 SC 2006.72.04.003887-4, Relator: ROGER RAUPP RIOS, Data de Julgamento: 12/05/2009, TERCEIRA TURMA)

“APELAÇÃO CÍVEL. AÇÃO DEMOLITÓRIA. CONSTRUÇÃO IRREGULAR EM ÁREA DE PRESERVAÇÃO PERMANENTE. AUSÊNCIA DE LICENÇA MUNICIPAL. MUNICÍPIO DE CABO FRIO. SENTENÇA DE PROCEDÊNCIA. RECURSO DO RÉU. 1. Incontroversa a inexistência de licença municipal para a construção da unidade habitacional. 2. Edificação irregular que serve de moradia para o réu e sua família. 3. A prova pericial produzida nos autos descreve a descaracterização de um loteamento no local, porém, o próprio réu reconhece que havia um loteamento original na localidade, a pressupor a possibilidade de ocupação humana. 4. Laudo pericial a demonstrar que, embora no interior da área vistoriada sejam encontrados elementos isolados remanescentes de mata atlântica de restinga e que haja ao fim da Rua Florestal mata remanescente com espécies de bioma de Mata Atlântica, não há mais área florestada no imóvel objeto desta ação, mas um conjunto de habitações, não se podendo validar a existência de APP à época dos fatos que remontam a ocupação do lugar. 5. Perícia técnica que revela através de fotografias que a edificação do réu serve de moradia para sua família e que na localidade houve uma evolução célere e severa da ocupação humana no local em que deveria haver um loteamento regularizado, desde o ano de 2007 até 2015, configurando uma área urbana consolidada por população de baixa renda. 6. O Código Florestal (Lei no 12651/2012), em seu artigos $7^{\circ}$ e $8^{\circ}$, dispõem sobre a possibilidade de o proprietário, possuidor ou ocupante do terreno recompor a vegetação que foi suprimida da Área de Proteção Permanente, bem como ser autorizada a supressão da vegetação de restinga e manguezais nos projetos de regularização fundiária de interesse social, em áreas urbanas consolidadas ocupadas por população de baixa renda. 7. Assim, restou configurada a colisão de um direito fundamental ligado intrinsecamente à garantia do princípio da dignidade da pessoa humana e um direito fundamental fora do núcleo essencial do princípio da dignidade da pessoa humana, qual seja, o direito ao meio ambiente ecologicamente equilibrado. 8. Prevalência da garantia do 
direito à moradia. 9. Dever da Municipalidade de buscar o controle e a vigilância permanente e preventiva da área para evitar novos desmatamentos, além de promover políticas de regularização fundiária e de saneamento básico para impedir maiores danos ambientais e sociais. 10. Inversão dos ônus sucumbenciais. Condenação do réu ao pagamento da taxa judiciária (Súmula ${ }^{\circ}{ }^{145}$, do TJRJ) e dos honorários advocatícios ao CEJUR/DPGE ora arbitrados em 10\% (dez por cento) sobre o valor da causa, nos termos do artigo $85, \S 3^{\circ}$, inciso I, e $\S 4^{\circ}$, inciso III, do CPC. 11 . Improcedência do pedido autoral. 12. Sentença reformada. Recurso provido.” grifei (TJ-RJ - APL: 00134489020098190011, Relator: Des(a). MARCO AURÉLIO BEZERRA DE MELO, Data de Julgamento: 04/09/2018, DÉCIMA SEXTA CÂMARA CÍVEL)

“APELAÇÃO CÍVEL EM MANDADO DE SEGURANÇA. ATO DO SECRETÁRIO DE INFRAESTRUTURA URBANA DE JOINVILLE. NÃO AUTORIZAÇÃO DE RECONSTRUÇÃO DE IMÓVEL RESIDENCIAL. SENTENÇA DE PROCEDÊNCIA. ÁREA DE PRESERVAÇÃO PERMANENTE. CURSO D'ÁGUA. REGIÃO DA CIDADE URBANIZADA EM TORNO E POR CIMA DO RIO, CANALIZADO POR MUROS DE CONTENČ̃̃O. FUNC̃̃̃O AMBIENTAL PREJUDICADA. CASO CONCRETO EM QUE A OBSERVÂNCIA DO \begin{tabular}{llllll}
\hline AFASTAMENTO & NO & IMÓVEL & ISOLADAMENTE & NÃO & TRARIA \\
\hline
\end{tabular} BENEFÍCIOS AO MEIO AMBIENTE. PRINCÍPIOS DA ISONOMIA, RAZOABILIDADE E DIREITO $\dot{A}$ MORADIA. INAPLICABILIDADE DA LEI 12.651/2012, DO CÓDIGO AMBIENTAL MUNICIPAL E DA LEI 6.766/79. SEGURANÇA MANTIDA. OBSERVÂNCIA DO AFASTAMENTO DE QUATRO METROS. APLICAÇÃO EQUIVOCADA DO CÓDIGO AMBIENTAL MUNICIPAL. AUSÊNCIA DE RECURSO DA IMPETRANTE. PROTEÇÃO AO MEIO AMBIENTE. MANUTENÇÃO DA SENTENÇA, POR FUNDAMENTO DIVERSO. RECURSO CONHECIDO E DESPROVIDO." grifei

(TJ-SC - AC: 00506637320128240038 Joinville 0050663-73.2012.8.24.0038, Relator: Vilson Fontana, Data de Julgamento: 08/11/2018, Quinta Câmara de Direito Público)

Nos julgados acima houve a preponderância do direito à moradia, considerando que no caso concreto a demolição e/ou despejos forçados implicariam violações aos direitos humanos, especialmente de vulneraveis, e não garantiriam a efetiva proteção do meio ambiente, considerando situações já consolidadas em razão de omissão estatal.

Assim, baseado na ponderação de Alexy, ao definir o sistema de normas relevantes ao caso concreto, ou seja, a existência de tensão entre meio ambiente e moradia; a seguir, numa segunda fase, a inter-relação dos elementos normativos, salientando-se a necessidade de superação do antagonismo, por se tratar de valores constitucionais relevantes; e, finalmente, na terceira fase, a necessidade de ponderação concreta, ou seja, a análise do caso concreto dos interesses e direitos em conflito; e a utilização do vetor imperativo: princípio do direito à moradia como preponderante no caso em análise. 
Por outro lado, indicando a preponderância do direito fundamental ao meio ambientente equilibrado, destacamos:

“AÇÃO CIVIL PÚBLICA. ÁREA DE PROTEÇÃO DE MANANCIAL E DE PRESERVAÇÃO PERMANENTE. PEDIDO DE CONCESSÃO DE USO ESPECIAL COLETIVO PARA FINS DE MORADIA. A hipótese dos autos não configura cerceamento de defesa. A Medida Provisória $n^{\circ}$ 2.220/2001 é constitucional. Precedente do Órgão Especial deste Egrégio Tribunal. A previsão de concessão de direito de uso especial para fins de moradia tem contornos de política pública e, como tal, plenamente cabível a imposição de limitação temporal, sem ofensa à Constituição Federal. Não preenchidos os requisitos para a concessão de uso especial para fins de moradia. A Resolução CONAMA no 369/06 está em consonância com o ordenamento jurídico e é plenamente aplicável. A área não está inserida em Zona Especial de Interesse Social, tampouco foi declarada como de interesse para a implantação de projetos de regularização fundiária de interesse social. Ausentes provas de que os moradores não sejam proprietários ou concessionários, a qualquer título, de outro imóvel urbano ou rural. REJEITADA A PRELIMINAR, NEGA-SE PROVIMENTO AO APELO." grifei

(TJ-SP - APL: 00087943620098260053 SP 0008794-36.2009.8.26.0053, Relator: Ruy Alberto Leme Cavalheiro, Data de Julgamento: 07/05/2015, $1^{\text {a }}$ Câmara Reservada ao Meio Ambiente, Data de Publicação: 14/05/2015)

"ADMINISTRATIVO. AMBIENTAL. CONSTRUCÃO EM APP. NÃO CARACTERIZAČ̃̃O DE POPULAC̃̃̃O RIBERINHA. PARNA ILHA GRANDE. AREA DE PRESERVAÇÃO PERMANENTE. O meio ambiente saudável como garantia de bem estar digno para esta e para as futuras gerações está constitucionalmente consagrado no art. 225 da CRFB/88. (...) O Parque Nacional Ilha Grande, criado em 1997, é originariamente área de preservação permanente na forma da Lei $n^{\circ} 4.771 / 65$, sendo vedada construção em detrimento do meio ambiente. Em que pese seja possível que no local houvesse, originariamente, uma moradia de ribeirinhos, população tradicional protegida pela legislacão nacional, o que se tem no momento, comprovado pelo conjunto fotográfico, é uma grande e nova construção sem qualquer finalidade de servir à população ribeirinha, nem havendo qualquer pessoa do gênero residente na área. Trata-se, então, de área adquirida para fins diversos (pesca esportiva e veraneio), que não guarda protecão legal em detrimento da preservacão ambiental.

(TRF-4 - AC: 50032290920164047004 PR 5003229-09.2016.4.04.7004, Relator: VÂNIA HACK DE ALMEIDA, Data de Julgamento: 04/06/2019, TERCEIRA TURMA)

CONSTITUCIONAL, ADMINISTRATIVO, CIVIL E PROCESSUAL CIVIL. AÇÃO CIVIL PÚBLICA. REEXAME NECESSÁRIO. CABIMENTO. PROTEÇÃO AO MEIO AMBIENTE. ARTIGO 225, CF/88. LEIS 4.771/1965, 6.938/1981, 7.347/1985, 12.651/2012. RESOLUÇÕES CONAMA 04/1985, 302/2002, 303/2002. OCUPAÇÃO E EDIFICAÇÃO EM ÁREA DE PRESERVAÇÃO PERMANENTE. DANO AMBIENTAL IN RE IPSA. RESPONSABILIDADE CIVIL OBJETIVA E PROPTER REM. TEORIA DO RISCO INTEGRAL. CONDUTA, NEXO E DANO COMPROVADOS. CONDENAÇÃO A OBRIGAÇÕES DE FAZER, NÃO FAZER, RESTAURAÇÃO AMBIENTAL E INDENIZAÇÃ̃O. APELAÇÃO DESPROVIDA. RECURSO ADESIVO E REMESSA OFICIAL PROVIDOS. (...) O desmatamento, ocupação ou exploração de área de preservação permanente, bem como a supressão de 
vegetação ou impedimento à sua regeneração em tais terrenos, configuram dano ecológico in re ipsa, o qual dispensa até mesmo prova técnica de lesividade específica e enseja a obrigação propter rem de restaurar a plenitude ambiental, indenizar pela degradação e igualmente terceiros afetados, sob a sistemática da responsabilidade civil objetiva. Significa, assim, que responde pelo dano não somente aquele que perpetra a ação lesiva como, de igual forma, quem contribui para sua manutenção. 6. Descabido falar em situação consolidada de ocupação de área de preservação permanente para evitar a ordem de desocupação e demolição das edificações nela erigidas, em nome da "razoabilidade e proporcionalidade", quando ausente licença ambiental para a supressão de vegetação nativa e ocupação do terreno, nos termos da lei, a revelar situação ab initio irregular. Não são admissíveis pequenas exceções que solapam a mens legis, ao argumento de serem imperceptíveis ou atenderem a interesses locais, pois seu conjunto agride o meio ambiente e causa evidente dano a toda a coletividade. (...) Equivocada a interpretação que o apelante faz do artigo $6^{\circ}$ da $\mathrm{CF}$. Os direitos sociais à moradia e ao lazer não são incompatíveis tampouco prevalecem em relação à garantia do inciso XXIII do artigo $5^{\circ}$ da Carta Magna de que a propriedade deve atender à sua função social, na qual se inclui resguardar o meio ambiente equilibrado para a presente e as futuras gerações. Assim, no caso de restar configurado tratar-se de local de preservação permanente, torna-se absolutamente impossível sua ocupação, pois é área da mais alta relevância ecológica, de prioritária proteção. 11. A infração ora analisada, ocupação não autorizada em área de preservação permanente, não se esgotou com o erigir das construções. Trata-se de conduta infracional continuada, que se protrai no tempo, porquanto contínua a utilização do espaço em desacordo com as normas de proteção ambiental, a agravar cada vez mais os danos ambientais no local, na medida em que impede a natural regeneração da vegetação. A jurisprudência admite que seja cumulada com a reparação, a qual, conquanto seja prioritária, não é suficiente para a reparação do malefício provocado. Ademais, seus objetos são distintos. A primeira objetiva compensar danos indiretos, passados, futuros, morais coletivos e tem efeito pedagógico, ao passo que a segunda busca a restauração direta e imediata. Precedente do STJ. 12. Apelo desprovido e recurso adesivo e remessa oficial providos, a fim de condenar o réu ao pagamento de indenização pelo dano ambiental causado, a ser quantificada em liquidação por arbitramento.

(TRF-3 - Ap: 00003841620104036006 MS, Relator: DESEMBARGADOR FEDERAL ANDRE NABARRETE, Data de Julgamento: 05/12/2018, QUARTA TURMA, Data de Publicação: e-DJF3 Judicial 1 DATA:24/01/2019)

Logo, para aplicação da ponderação e sopesamento entre principios igualmente relevantes, conforme preconizado por Alexy, primeiramente o julgador difiniu o sistema de normas relevantes ao caso concreto, ou seja, a existência de tensão entre meio ambiente e moradia; a seguir, numa segunda fase, a inter-relação dos elementos normativos, salientando-se a necessidade de superação do antagonismo, por se tratar de valores constitucionais relevantes; e, finalmente, na terceira fase, a necessidade de ponderação concreta, ou seja, a análise do caso concreto dos interesses e direitos em conflito; e a utilização do vetor imperativo: princípio do direito ao meio ambiente equilibrado como preponderante no caso em análise.

Revista de Direito Urbanístico, Cidade e Alteridade | e-ISSN: 2525-989X | Belém | v. 5 | n. 2 |

p. 63 - 80 | Jul/Dez. 2019. 
Note-se que baseado na mesma premissa e mesma técnica o julgador concluiu por resultados opostos, de maneira que o elemento definidor foi não a norma em conflito, mas o caso prático sub-judice, sendo certo que nos casos analisados, embora as conclusões tenham sido antagônicas, a análise do caso concreto demonstra que todas foram justas.

Assim, ao final, por mais que seja louvável a preocupação com a preservação do meio ambiente ele não pode fazer com que os objetivos fundamentais da República da erradicação da pobreza e a redução das desigualdades sociais sejam descuidados. A preferência pela conservação das Áreas de Preservação Permanente sobre a garantia do direito à moradia só deverá ocorrer quando estas áreas forem realmente imprescindíveis para a garantia de um meio ambiente ecologicamente equilibrado e não estando presentes outros elementos de vulnerabilidades.

\section{CONCLUSÃO}

Verificamos no presente estudo que, se por um lado, tem-se o direito fundamental à moradia assegurado constitucionalmente, por outro lado, notório o aumento demográfico e a dificuldade do Estado prover a efetivação de políticas públicas para implemento dos direitos sociais para ordenado desenvolvimento e auxilio às classes mais vulneráveis, provocando a segregação espacial da população de baixa renda, restando à estes as áreas marginais que, muitas vezes, são áreas de preservação ambiental.

De outro lado, temos meio ambiente ecologicamente equilibrado, igualmente tutelado na Carta Magna, impondo-se ao Poder Público e à coletividade o dever de defendê-lo e preservá-lo para as presentes e futuras gerações.

$\mathrm{O}$ direito à moradia goza de ampla proteção internacional e é apontado como um elemento essencial para dignidade da pessoa humana, da mesma forma a proteção do meio ambiente é fundamental para o bem-esta das gerações presentes e a sobrevivência das futuras, pelo quê incontroverso que ambos devem receber ampla proteção e efetivação pelo Estado. Assim, ambos são fundamentais, consituicionamento previstos e por isso tratados pela doutrina como princípios, pelo quê devem conviver em harmonia em razão de inexistir hierarquia entre as normas constitucionais. Não são absolutos, razão pela qual no caso de conflito entre referidos 
direitos, o Poder Judiciário, no caso concreto, tende a ponderar os dois interesses constitucionais, de modo a preservar o núcleo essencial de cada um, encontrando a decisão mais adequada e justa à lide.

A preocupação com a preservação do meio ambiente não pode resultar na aquiescência com a perpetuação de uma realidade social trágica vivida por parte significativa parcela da população. Assim, quando as áreas protegidas pela legislação ambiental não forem imprescindíveis para o equilíbrio ambiental, como as áreas às margens de rios que proveem recursos hídricos para a população e em áreas muito íngremes, casos em que a manutenção das moradias apresentam um risco real e mediato para a sociedade, o direito à moradia deverá ser resguardado.

A análise dos julgados, em destaque no item anterior, indica que aplicando a ponderação proposta por Alexy a definição do resultado submete-se ao arbítrio de quem a realiza, logo, teremos a obtenção de resultados diferentes face o conflito dos mesmos principios (moradia e meio ambiente equilibrado). Assim, não existe uma decisão única, pronta e acabada para o caso de conflito entre o direito fundamental à moradia e o direito fundamental ao meio ambiente, de maneira que os dois direitos fundamentais, ora prevalesceu o direito à moradia, ora prevalesceu o direito ao meio ambiente, e todas as decisões foram justas, fundamentadas e adequadas ao caso concreto, zelosas quanto à preservação do núcleo essencial de cada direito envolvido, de modo a harmonizar e manter a ausência de hierarquia entre referidos direitos, bem como a unidade da Constituição.

Neste contexto, embora a ponderação proposta por Alexy seja aberta, respeita elementos e critérios do caso concreto, sendo portanto sempre dinâmica quardando consonância com os anseios sociais, viabilizando interpretações globais, afastando-se as antinomias e possibilitando a máxima efetividade, evitando-se o sacrifício de um princípio em relação ao outro em confronto.

\section{REFERÊNCIAS}

ALEXY, Robert. Trad. de Menelick de Carvalho Netto. Direitos Fundamentais, Balanceamento e Racionalidade. Ratio Juris. Vol. 16, n. 2, junho de 2003 (p. 131-40) da Faculdade de Direito da Universidade Federal de Minas Gerais. 
BASTOS, Celso Ribeiro. Curso de Direito Constitucional. Rio de Janeiro: Celso Bastos, 2002.

BOBBIO, Norberto. A era dos direitos. 11. ed. Rio de Janeiro: Campus, 1992.

. Trad. de Marcio Pugliesi, Edson Bini, Carlos E. Rodrigues. O Positivismo Jurídico:

Lições de Filosofia do Direito. São Paulo: Ícone, 2006.

LEITE, Luis Felipe Tegon C. Cartilha Regularização Fundiária MPSP, 2017, p. 6. Disponível em: http://www.mpsp.mp.br/portal/page/portal/Cartilhas/2017\%20-\%20Cartilha\%20regulariza\% C3\%A7\%C3\%A3o \%20fundi\%C3\%A1ria.pdf. Acesso em: 30.04.19

MELO, Lígia. Direito à moradia no Brasil. Política Urbana e Acesso por meio da regularização fundiária. Belo Horizonte: Fórum, 2010.

SAULE JÚNIOR, Nelson. A proteção jurídica da moradia nos assentos irregulares. Porto Alegre: Sérgio Antônio Fabris, 2004.

SERRANO, Pablo Jiménez. Teoria do Direito: Contribuição ao Pensamento Jurídico Contemporâneo. $1^{\mathrm{a}}$ ed. Rio de Janeiro: Jurismetre, 2017.

SILVA, José Afonso da. Direito Ambiental Constitucional. 6. Ed. São Paulo: Malheiros, 2007.

STRECK, Lenio Luiz. Hermenêutica Jurídica e(m) crise. 5. ed., Porto Alegre: Livraria do Advogado, 2004. 